\title{
Identities at Odds - embedded and implicit Language Policing in the internationalized Workplace
}

\author{
Spencer Hazel
}

Department of Culture and Identity, Roskilde University, Roskilde, Denmark

\section{Introduction - overview}

Workplaces around the world have increasingly come to be constituted as communities of transnationally mobile staff and clientele, and the resulting cultural and linguistic diversity to which this gives rise. One consequence is that members of these transient multilingual communities (Mortensen, 2013) need to coordinate dynamically fluctuating participation frameworks (Goffman, 1981; Goodwin 1981; 2007) and their contingent language scenarios (Mortensen, 2010) as part and parcel of their ongoing daily workplace activities (e.g., Torras, 2005; Hazel \& Mortensen, 2013). This in turn requires members to remain sensitive to a shifting bricolage of linguistic identities (Gafaranga, 2001) encountered at any given moment as they go about their work-related activities, in order to be able to respond appropriately, effectively and efficiently to each linguistic scenario as it arises. Consequently, a member's language competencies can become implicated in his or her institutional and thereby also implicitly their professional - identity.

The current study offers an empirical, interaction analytic account of how linguistic identities are indexed against members' institutional positions in particular workplace interactional settings such as business meetings and university helpdesk service encounters. Drawing on Conversation Analysis (Goodwin \& Heritage, 1990, hereafter CA) and Membership Categorization Analysis (Hester \& Eglin, 1997, hereafter MCA), the study demonstrates how members topicalize linguistic identities that go against normative expectations, implicitly engaging in language policing at a praxeological level, and treating members of the workplace community who do not meet with expectations regarding language repertoires as deviant or even sanctionable. The paper will argue for greater attention to be paid to the actual language-political practices in international workplace settings, as an entry point into developing a more nuanced understanding of the practices through which professional identities are brought about, affirmed and contested, and the linguistic considerations that are implicated in this. This would complement research strands that investigate language policy, ideology and attitudes through a focus on official documentation, or by drawing on qualitative research methods such as focus groups and interviews.

A growing number of institutions have moved to adopt formal policies pertaining to language practices - including that at the level of language choice - in the workplace (e.g., Nekvapil \& Nekula, 2006; Lønsmann, 2011; Neeley, 2013; Angouri \& Miglbauer, 2014; Gunnarsson, 2014; Hultgren, 2014). Such explicit language policing may be introduced to respond to the changing demands that result from increased globalisation, including the internationalized make-up of a particular institutional community, be it for example a company operating across borders or with greater numbers of migrant professionals, foreign-based clients or partners in other parts of the world, at popular tourist attractions, or at particular institutional programmes within tertiary-level education. However, such language policy strategies may not apply, or be appropriate, to all settings within a workplace community, or indeed reach the relevant parties. For example, in the case of a university seeking to 
develop an international profile, students, maintenance staff, canteen employees, language teachers and administrators may each have different levels of access, lines of communication, or levels of investment in the organization's formal language policy. Furthermore, individual members may also hold entrenched ideological positions of their own pertaining to the relative value of the use of particular languages within a setting, or to language requirements relating to institutional positions within a particular workforce. Hence, backroom language policies may not be implemented or adhered to across all settings within a workplace community, and this necessitates members to remain prescient to the dynamics of such transient multilingual settings (Goebel, 2010).

In linguistically dynamic environments where language choice is then not predetermined by formal institutional policy (for example relating to language use among technical support staff (Lønsmann, 2011) or in informal or liminal institutional settings (Hazel \& Mortensen, 2013), selecting or negotiating a medium-of-interaction may become a relevant activity to which interlocutors need to attend (Auer, 1984; Torras, 1998). Within groups that enjoy a more or less stable membership, these practices can rely on prior experience and knowledge of other members' linguistic repertoires and preferences (Spolsky, 2007; Bonacina-Pugh, 2012). Members can draw on experience of interacting with particular colleagues, clients or partners, in order to select the appropriate language to use with them, or which bilingual mode (Gafaranga \& Torras, 2001) to adopt. In addition, they may switch to a designated corporate language when engaged in particular types of activities, such as team meetings (Lønsmann, 2011) or student project group activities (Mortensen, 2010). Here, where language policy may not be explicitly discussed between members, it is still embedded in how participants micro-manage their interactions. Consequently, the locally determined language policy for the particular interactional setting can be located in how a medium-of-interaction is negotiated and/or enforced by members, without it being overtly topicalised in the talk. For example, Mortensen (2014) shows how locally established norms for language choice within student project groups are evidenced in how the members orient to the appropriateness of one or other language for engaging in particular activities, such as on-task or off-task talk. Elsewhere, in encounters where participants have no prior experience of interacting with one another, participants must also work together to alight upon the medium which best suits the parties involved and the institutionally oriented activities in which they are engaged (Heller, 1982; Torras, 1998). Especially at the incipient stage where people move from co-presence-in-space to being co-participants-in-interaction, we are able to distil from the sequential organization of social actions - including that at the level of language choice - who and what people are expected to be - institutionally, professionally - in these settings (see Hazel \& Mortensen, 2014; Mortensen \& Hazel, 2014).

\section{Methodological approach}

The line of research offered here builds on notions of the "linguistic realisation of institutionality" (Kurhila, 2006, p7; Heritage, 1997). From this perspective, the institutionality of interaction is constituted through how participants' themselves attend to the setting, and the particular participation frameworks (Goffman, 1981; also Goodwin, 1981, 2007) upon which an interaction is contingent, including how institutional identities are constituted in situ. 
Social science has occasioned a number of lines of investigation characterized by a focus on situated social action and interaction observed in their natural everyday habitats. The methodological perspective applied in the current study has its origins in the American sociological approach to language and social interaction, known as Ethnomethodology (Garfinkel, 1967; henceforth EM). In EM, the study of human sociality is premised on an understanding that there are methods of which members of a society avail themselves in their understanding, production and navigation of their social world. It is the researcher's goal to explicate these members' methods for conducting social life (hence Ethno-methodology), rather than impose a priori theoretically derived categories, as is common in a majority of social scientific work. Social order is considered here an achievement by the participants, who rely on their common-sense knowledge of situated action in order to accomplish, in situ, orderliness in their conjoint social activities.

The EM approach has inspired a number of lines of research, most notably Conversation Analysis (Sacks, Schegloff \& Jefferson, 1974) and Membership Categorization Analysis (Sacks, 1972; Hester \& Eglin, 1997). Both approaches take as a central concern that sociality must be understood from the viewpoint of the participants engaged in social life: CA in investigating the systematic practices oriented to by participants in the sequential organization of social action, and MCA by explicating the procedures through which members associate particular activities or characteristics - predicates - with particular categories of people (Sacks, 1972). Such research explores

"the relevance of person categorization to the understanding and assessment of conduct, and the consequent importance of understanding how categories are made relevant, even if tacit, in ordinary conduct of interaction" (Schegloff, 2005, p474)

Sacks proposed that these membership categories are "inference-rich" (Sacks 1992, p40) with members displaying their understandings of particular characteristics that are accepted as common knowledge about members of the category (Sacks 1979, p13).

By investigating the practices members themselves employ to display their understanding of ongoing activities between one another, a researcher is able to shed light on the very dynamic constitution of social order through members' own methods for social engagement. With CA and MCA using audio- and increasingly audiovisualrecordings of - and artefacts stemming from - social engagement in its natural ecology, the research methodology offers powerful tools to unpack and describe the situated social processes involved in workplace organization.

Consequently, these lines of investigation have been strongly represented in applied research, highlighting the situated nature of social action, with important interaction analytic research being carried out in such institutional sites of engagement as business meetings (e.g. Markaki et al, 2010; Mondada, 2004), collaborative workplace activities (e.g. Murphy, 2005), healthcare (e.g. Brassac et al, 2008; Heath, 2002; Koschmann et al. 2011), public space milieu (e.g. Hindmarsh et al, 2005; Mondada, 2009), educational and instructional settings (e.g. Goodwin, 1994; Greiffenhagen \& Watson 2009; Mori \& Hasegawa, 2009; Mortensen \& Hazel, 2011; Nishizaka, 2006), and public broadcast media (e.g. Raudaskoski, 2010).

The present study aims to contribute further to this field, investigating what implications the widespread internationalisation of workplace settings has for the members, including the interactional competencies relevant to the navigation of such interactional settings. One salient area of internationalisation relates to the impact on 
the participants with regard how a members' language competencies are implicated in their institutional - and thereby also implicitly their professional - identity. We turn now to build an empirical account of some such displays, and to demonstrate how deviation from normative interactional patterns by members of the community can impact upon their status as member of their institutional category.

Data for the current study were collected by the author in internationalised workplace settings, including international university settings ${ }^{1}$ (see Hazel, 2012), and international companies in Denmark ${ }^{2}$. Video-, and in some cases, audio-only recordings were produced using multiple recording devices for optimal coverage. Transcription conventions are based on those developed by Gail Jefferson (e.g., 2004) (further explanation provided at the end of the text).

\section{Language policing - situated language policies in practice}

Spolsky $(2004 ; 2007)$ differentiates between three levels of language policy: that found in language management (the formally agreed instruction and documentation), in beliefs (what people hold to be appropriate conduct) and in practice (what people actually $d o$ ).

... language practices, beliefs and management are not necessarily congruent. Each may reveal a different language policy. The way people speak, the way they think they should speak, and the way they think other people should speak may regularly differ. Looking at the language policy of established nations, one commonly finds major disparities between language policy laid down in the constitution and the actual practices in the society. Within social groups, it is common to find conflicting beliefs about the value of various language choices. One is therefore faced regularly with the question of which the real language policy is. (Spolsky, 2004: 217)

By this reasoning, social practices relating to language use are considered to constitute an actualization of a particular community's policies concerning appropriate conduct, including of course that at the level of language choice. Through such practiced language policy (Bonacina-Pugh, 2012), participants draw on regular patterns of language usage, with "practice form[ing] a recognisable and analysable set of patterns" (Spolsky and Shohamy 2000: 29). These in turn constitute interactional norms. As Bonacina-Pugh (2012: 219) writes:

...interactional norms are the implicit understanding that speakers have of what language (choice) act is appropriate or not in a given context. Speakers use these norms as "schemes" (Garfinkel 1967) to interpret each others' language (choice) acts; that is, "a point of reference or action template for interpretation" (Seedhouse 2004: 10).

Regularity, recognizable practices and underlying norms may point to relatively stable communities, where members rely on shared understandings, and members whose practices do not correlate with overall normative expectations may be interpreted by others in the community as somewhat deviant. Indeed, they may be treated as such also. These deviant cases can be identified through participants displaying an orientation to the particular conduct/act as requiring repair, or being marked in some way or other. By looking at the ways the participants treat these interactional moments, an analyst is able to identify the related normative

\footnotetext{
${ }^{1}$ These data were collected as part of the Research Centre for Cultural and Linguistic Practices in the International University (CALPIU).

${ }^{2}$ Carried out as part of the LINGCORP Research project.
} 
expectations. Furthermore, they offer valuable insight into the ways in which members of a community are constituted as being deviant.

\subsection{Embedded language policing}

The following example is taken from a departmental meeting situated in an international company in Denmark, composed by a nationally heterogeneous workforce where transnational mobility is a common feature. The meeting has until this point been conducted in English, which here acts as a regularized lingua franca for this type of activity - between the participants, who are from different European countries $^{3}$. There are 8 participants present, most of whom have at least some proficiency in Danish, and all who are able to use English, albeit with differing levels of proficiency. The practiced language policy in evidence here - with English adopted as a corporate lingua franca - appears to be premised on how the team is constituted through members from different language backgrounds, and with new members joining and others leaving the team on occasion to work in other departments within this multinational company.

At the point of entry into this sequence, the Team Manager (ULLa) is talking with one of the team members (EMMa) about work at home days near the Easter break. As she does this, a third member of the team (ANNa) interjects with a comment.

\footnotetext{
3 Prior to the formal proceedings of the meeting commencing, as well as during breaks in the meetings, participants use other languages also.
} 


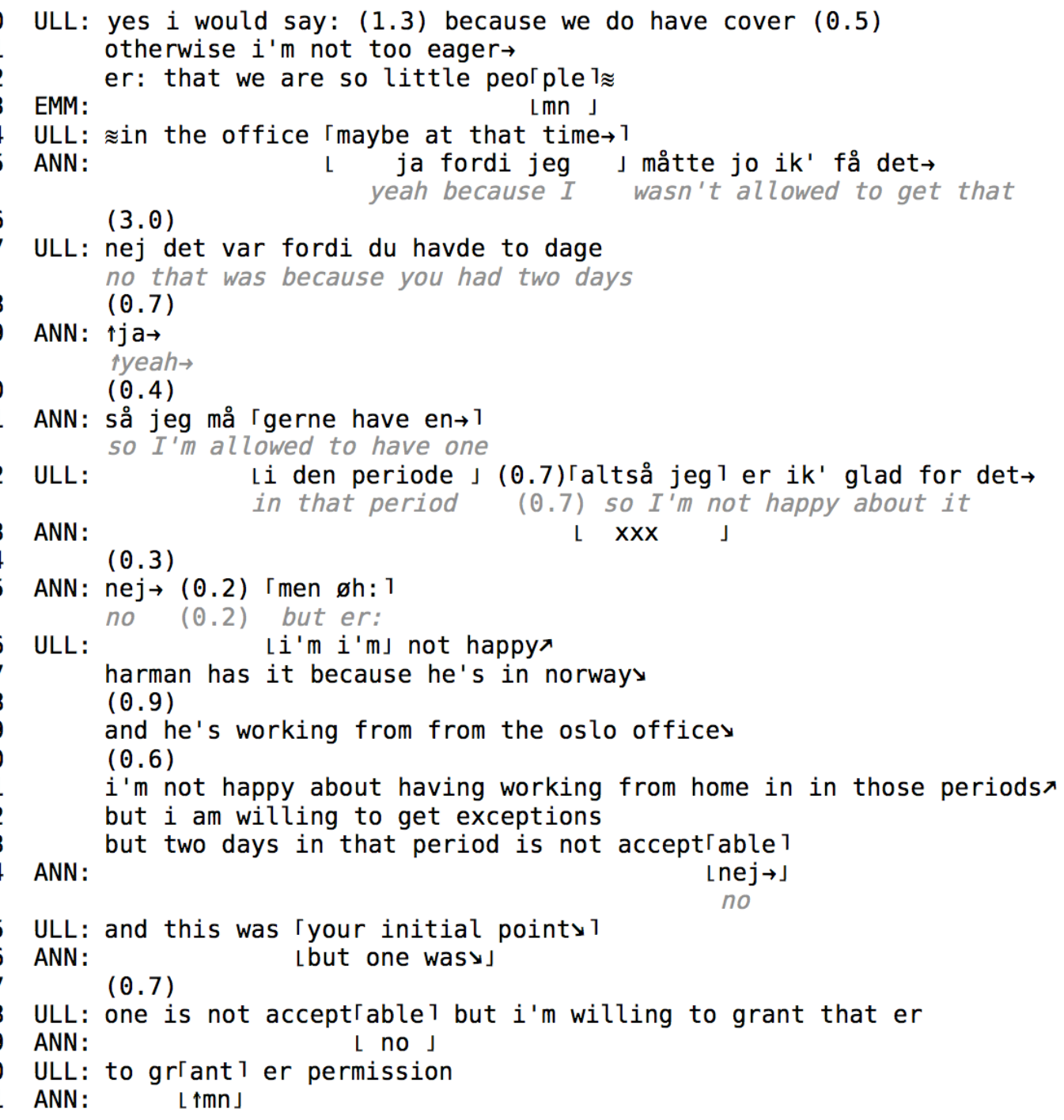

We note in the example how Anna provides a critical comment to her line manager Ulla (line 15), where she raises an issue relating to her own request for work-at-home days, a decision where she feels she has been slighted. Importantly, we see how this interjection is treated as the voicing of a grievance by the manager Ulla, who in response provides an account for the decision (lines $17 \& 22$ ). This appears then to evidence a workplace culture where managers can be challenged by their subordinates, and explicitly held to account for their decisions. Not only do we observe the challenge, but we also see that the manager orients to this as - not necessarily a welcome trajectory - but valid all the same. Although complaints make a variety of responsive turn- or action-types relevant (Schegloff, 1984), for example remedial actions, excuses, apologies and the like, here Ulla produces an account for her decision to only allow Anna a single extra work-at-home day. Although the complaint is thus not addressed in a remedial way, but instead rejected, the rejection is formatted as a dispreferred response (on preference organization, see Pomerantz 1984): it is delayed, it includes an account for the decision, and furthermore mitigates the rejection with a further account of how Ulla has already gone out of the way to make exceptions.

Pertinent to the study here, we note that the language chosen for providing the 
comment in line 17 is Danish, not English as the rest of the meeting, and the side sequence that this occasions is initially pursued in Danish. Auer (1984) has proposed that there is a normative preference in conversation for maintaining the same language across turns at talk (see also Gafaranga, 2000 on same medium talk; Nevile \& Wagner, 2008). In this way, the choice of language used in a first pair part adjacency pair (for example a question) constrains the choice of language through which a second pair part (e.g. an answer) is produced. In the current sequence, this means that the unmarked choice for the manager here is to respond in Danish, which she does.

However, Ulla subsequently does initiate medium repair (Gafaranga, 2000), where she repeats her utterance initially produced in Danish ('jeg er ikke glad for det', line 22) subsequently in English ('I'm not happy' line 26). We see that this repair is initially resisted by Anna: her acceptance of the account in line 34 is still distinctly Danish ('nej'), but eventually she complies with the medium repair, displaying her understanding of the manager's account, which she formats both as an increment to Ulla's 'but two days in that period is not acceptable' (line 33), with her own 'but one was', (line 36), now in English.

We note then that in this interactional setting - a departmental team meeting - some challenges are legitimated, but at the level of language choice, Anna's opting for Danish is treated as unacceptable. Indeed, not only does the manager perform a dispreferred action in the form of an other-initiated repair (on preference organisation and repair, see Schegloff, Jefferson \& Sacks, 1977) she formats the medium repair without any of the components that would normally mitigate for the dispreference of the action (these could be, for example, delay, hesitation markers, inter- and intra turn pauses, or an account for the repair). Robinson describes how the withholding of such formatting components "tend[s] to have negative sociorelational implications" (2004: 320 ), but it can also act as a contextualization cue for inferring a particular range of social actions being performed, for example teasing, arguing, some jocular activity, or producing a complaint. In this case, with such components withheld by Ulla, the repair appears formatted as an unequivocal, public rejection of Anna's language choice, and Anna is brought to book on the matter, in full view of her colleagues.

The example demonstrates how when members display language choice preferences that do not correlate with the prevailing practiced language policy (in the sense described by Spolsky and Shohamy (2000) and Bonacina-Pugh (2012)), they can be publicly sanctioned, with their language selection overruled. Indeed, even in workplace settings such as these where we observe a predominantly democratic organisational ideology being oriented to, where subordinates' personal opinion is not only accepted, but valued and encouraged, members of staff can have their choice of language overridden, regardless of the fact that it may be the better language through which to communicate with their interlocutor ${ }^{4}$. Of course, a manager who must operate with a fluctuating team of transnationally mobile employees who each have different linguistic repertoires, career trajectories within the company, and histories within the local setting, is faced with the issue of maintaining optimal lines of communication between team members. This includes transparency, where decisions are understood by all, not just those more closely connected. Ulla's embedded language policing here results in all team members being included as ratified overhearers (Goffman, 1981) to what is ostensibly a private complaint sequence between her and her subordinate.

\footnotetext{
${ }^{4}$ Interestingly, Anna, who appears to be insisting on a right to use Danish with her Danish manager, is not herself a Dane, but is from Sweden (albeit someone who has lived in Denmark a number of years), and appears therefore to be claiming the right to use a different L2 than English.
} 
Although this example is drawn from a transient multilingual setting, there is enough group stability for practices to become routinized, even within the ongoing changing membership of the team. Elsewhere, however, members face the necessity of having to enter into encounters with people they have never met previously. Here, participants must coordinate or negotiate language policy practices on the spot, including at the level of appropriate language choice. As they do so, so we gain access to normative expectations relating to the matter. It is this that we turn to now.

\subsection{Implicit language policing}

\subsubsection{Membership categories and their linguistic predicates}

Parties entering into an interaction with a previously unacquainted person in a linguistically heterogeneous setting are faced with the member's concern of which language to opt for from the outset. A number of resources appear to facilitate them in settling on an operational medium for interaction. Some of these relate to membership categorization, through which they may project certain expectations relating to the language competencies and preferences of their incipient partners-in-interaction. Not all membership categories here are relevant. Gender, for example, sexual orientation or age group categories would be wholly irrelevant to the linguistic identities of the interlocutors-to-be.

However, there are membership categories - for example those pertaining to ethnic or racial background, geographic residence, or institutional identity - that appear to be used as a resource for discerning the probability for possible language preferences or competencies on the part of the unacquainted other. Someone with an East-Asian appearance may, for example, be judged less likely to have proficiency in Portuguese, than someone with Latin-American features. Regardless of the obvious margins of error that such categorisation practices engender, people seek to reduce the levels of complexity when faced with social life in all its messy, diverse glory. By categorising the members we encounter into social sub-categories of varying granularity, we draw on normative expectancies regarding such membership categories and the presumed characteristics and features associated with them (Antaki \& Widdicombe, 1998).

In addition to the many 'transportable identities' (Zimmerman, 1998) described above, social identity constructs constituted in interaction may be drawn on to furnish participants with further cues regarding the appropriacy of a particular language choice for the setting. Here, identities are brought into being discursively, worked up as respective relational identities relevant to the interaction in which they are engaged (for example, parent, mechanic, nerd, punk, swinger). As with the identity constructs described above, these membership categories too may engender particular associations, e.g. a particular dress code for a punk, a particular laisez-faire attitude for a swinger. It follows that such membership category predicates are useful tools, but only when the particular social identity is oriented to as being relevant to the business at hand.

As with the 'transportable identities', particular membership categories may also imply particular linguistic implications, including preferences for language choice in a particular setting, and linguistic repertoires and competencies. As way of illustration, consider the following extract, which serves to demonstrate how linguistic identities are implicated in certain social membership categories. Here, MARianne is standing behind the help desk counter at an International Office in a Danish university, when ANIta and BRIgitta approach. 


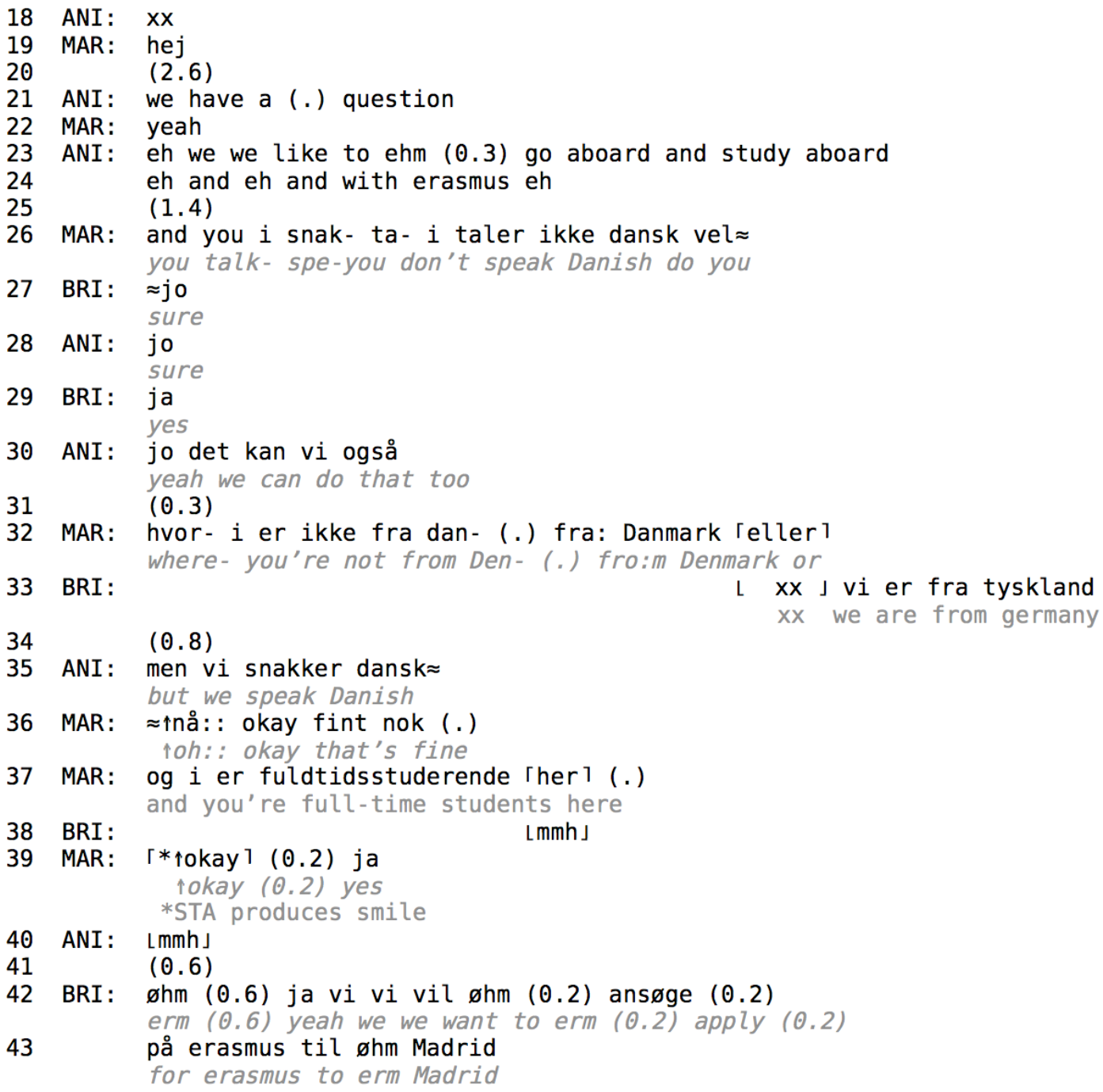

Anita initiates her account for attending the helpdesk in English (lines 21 \& 23). She does this immediately, without any preliminary request as to whether this is an appropriate choice. This displays an projection on her part that the member of staff is able to deal with the service encounter in English, and that this language selection would be neither problematic, nor unexpected, for the given setting. For her part, the staff member triggers a switch to Danish once it becomes clear what is projected as the topic of the service. As soon as Anita announces that the students are interested in a study exchange abroad (line 24), she asks whether they are Danish speakers (line 26). This is not surprising, as the programme after which the students are enquiring is intended for full-degree students at the university, the overwhelming majority of which are Danish. Offering Anita and Brigitta the opportunity to conduct the encounter in Danish suggests that the normative expectation is that these encounters are conducted in the language 'of least resistance', at least on the part of the client (we return to this in the analytic sections below).

The staff member initially responds in English (line 26), though breaking off almost immediately and switching to the local language for the remainder of the turn, in which she asks whether or not they speak Danish. Interestingly, she projects her understanding that they are Danish speakers through the language choice in which she 
produces the question, namely Danish. The students confirm that they are able to speak Danish, which calls attention to their capacity to use of the language, rather than it being their default. This in turn prompts the staff member to offer a further candidate understanding that they are not from Denmark (line 32). Brigitta confirms this, in Danish, by self-categorizing herself and her partner as hailing from Germany.

We observe then how the staff member's initial categorisation of the students as Danish occasions an extended insertion sequence (Schegloff, 1972) in which this misunderstanding is straightened out. In addition, the participants orient to the students' Danish proficiency as somewhat non-normative. Having first categorized them as Danish speakers, the staff member produces a change-of-state token (Heritage, 1984) with an upward pitch shift ( $\uparrow$ nå::, Eng. $\uparrow$ oh::), indicating a shift in understanding, that they are not from Denmark after all. Subsequently, when Brigitta categorizes herself and Anita as being 'from Germany', Anita orients to their still being able to speak Danish as somewhat marked, through her use of the modifying phrase 'but we speak Danish'. It appears here that participants orient to the category 'international student' with a predicate 'non-Danish speaking' constituting the norm here, with 'Danish speaking foreign students' representing a smaller sub-category. Indeed, the staff member's candidate formulation in line 37, proposing they are fulltime students, may also reflect an understanding that that this particular sub-category, the full-time student, would account for their Danish language proficiency, as opposed to other sub-categories of international students, such as exchange- or visiting students. Although Anita has already set out that they would like to discuss studying abroad, which categorises them as full-time students at the university, the staff member's response to Brigitta's confirmation of this line, 'okay' (line 39), is formatted as a change-of-state token (Heritage, 1984) with a marked upwards shift in pitch. This suggests that she has now been able to fully re-calibrate the categorization of the students, bringing the insertion sequence to a close. Anita subsequently reformulates her earlier turn in which she set out the reason for the visit, this time in Danish (lines 42 \& 43).

The above analysis illustrates how membership categories such as 'international student', 'German', 'full-time student' and 'university international staff member' may be used by members to project the linguistic make-up of those they come into contact with. Where reality intervenes and expectations are uncorroborated, work is undertaken to re-calibrate the misalliance between expectation and actuality. In what follows, we will explore this further, and demonstrate how such sequences of misalignment between institutional and linguistic identity may act to undermine the institutional position of a member of the community, by orienting to them as not typefitting the institutional position relevant to the encounter. This, I will argue, is a form of implicit language policing, where members are treated as not conforming to their professional identities, on the basis of an absence of some or other expected linguistic resources.

\subsubsection{Institutional identity and orientations to deviance in language repertoire}

Although the public sanctioning of the sort observed in Example 1 may display the various power relations at play in dyadic engagements where there are formal divisions of labour and status, language policing can also be found in other participation frameworks, such as that described in the following examples, and where language preferences and competences are indexed against someone's institution-bound social identity. In the following analysis, we will start by 
introducing a particular recurrent practice for entering into a service encounter at a university International Office help desk (see also Mortensen \& Hazel, 2014), before moving to discuss one of a collection of deviant cases.

Across all types of approach, a common pair of patterns for entering into the focused encounter is represented in the following transcripts:

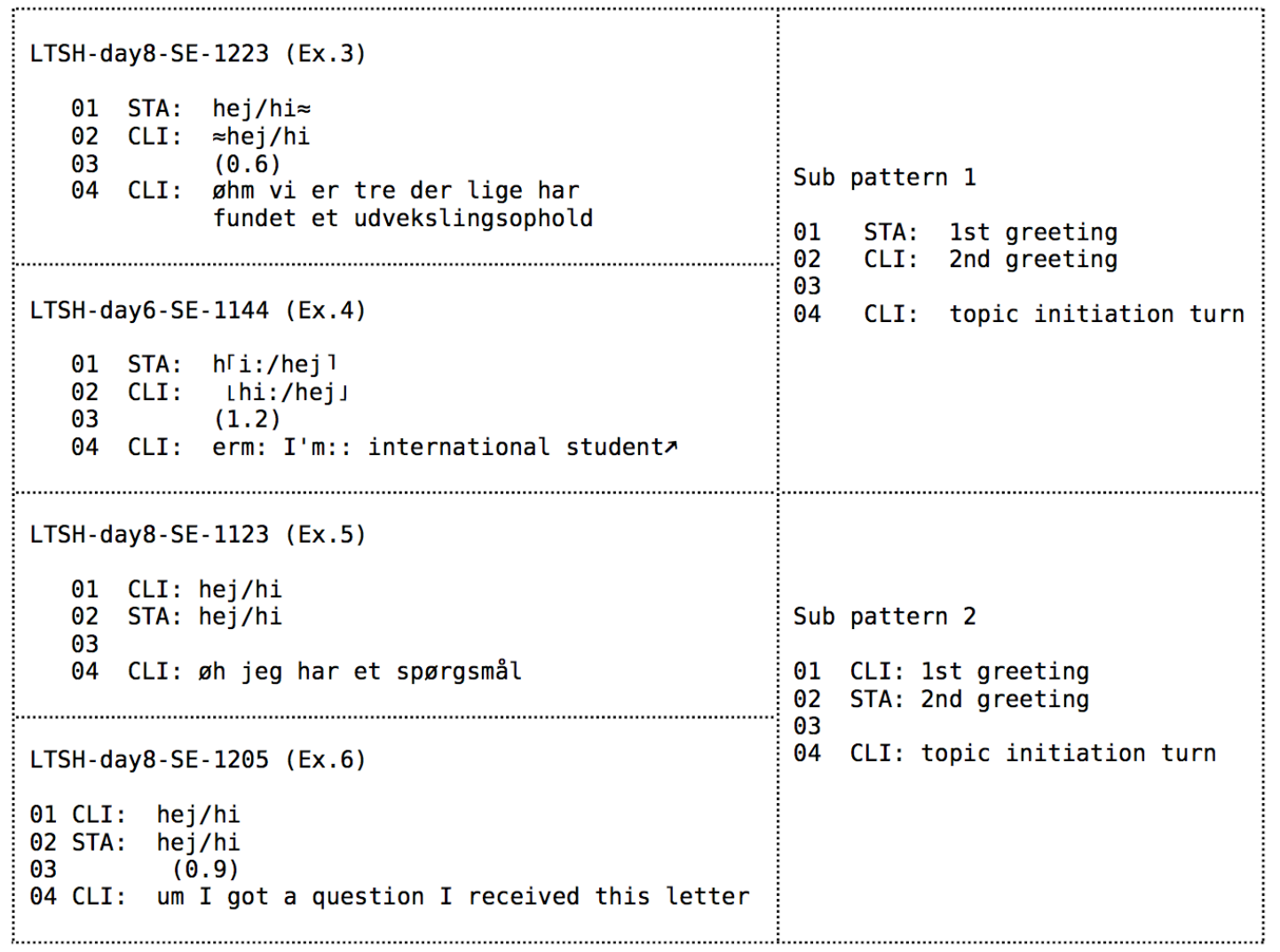

In these examples, we note a canonical adjacency sequence of greeting tokens, here 'hi' or 'hej', a subsequent hesitation marker (for example 'erm' or 'øhm') which acts as a pre-speech token indicating upcoming speakership, following which the client starts formulating the reason for the visit.

Although a Danish greeting 'hej' and an English 'hi' can sound distinctly different, to those unacquainted with Danish, they can sound very similar ${ }^{5}$. Further, in these settings there is both a great deal of variation in how this greeting is vocalized. The upshot is that the linguistic code is at this stage ambiguous ${ }^{6}$. This linguistic ambiguity acts as a resource for negotiating the medium-of-interaction for the subsequent encounter. We note two patterns: the first involves the staff member (STA) producing the first greeting with the client (CLI) responding. In this pattern, the initial 'ambiguous' hej/hi greeting token is responded to with a similarly ambiguous return greeting from the client. This allows for the client to respond in the same language

\footnotetext{
${ }^{5} \mathrm{~A}$ reviewer of the current article has pointed out that if these greeting tokens are produced with rising intonation, it is likely to be heard as a Danish ' $h e j$ ' rather than and English ' $h i$ '. This would definitely be the case for many settings. However, the data from this setting does not seem to bear this out, as there is a great deal of variation in how he L2 users of both English and Danish produce these tokens, including at the level of intonation contour. Participants are unable, then, to treat this as a reliable marker for the use of hej or hi.

${ }^{6}$ See Woolard, (1999) and Torras (1998) for discussion of bivalent utterances, tokens that could be heard as being from either one language or another, such as the Catalan and Spanish 'hola'.
} 
and proceeding to the next turn where the medium becomes disambiguated, either as Danish as in the first example, or English as in the second. The second pattern has the $1^{\text {st }}$ greeting produced by the client, with the member of staff producing the return greeting. Here, the staff member is in the position to treat the $1^{\text {st }}$ greeting (produced by the client) as either Danish or English. The client is then in the position to treat this return greeting as either Danish or English, and to proceed to formulate the next turn in that medium-of-interaction.

The above patterns for entering into a service encounter at this International Office help desk evidence a particular organization of affording the client the right to select one of a number of languages to serve as medium-for-interaction, here Danish or English. It is always the client who is afforded the turn where the language becomes disambiguated. This in turn demonstrates categorization work carried out by the participants, who at this incipient stage of their focused encounter are able to display within their turn organization an institutional orientation, with an asymmetrical distribution of interactional rights and obligations. Secondly, these membership categories are linked with particular category bound associations relating to language repertoires. Particularly, the category 'International Office staff member' is oriented to as having the linguistic arsenal to deal with a client in whichever language the client selects (from the collection consisting of Danish and English).

Routinized practices such as those described here pass off in an unmarked - seenbut-unnoticed - fashion, as has been described for normatively appropriate social conduct in general (Garfinkel, 1967). Analyses of cases that deviate from the regular interactional patterns can provide us with a useful second level of analysis. These instances provide us with further insight into what normative expectations are present, according to which parties orient themselves in the particular setting at hand. Deviant cases can be identified through participants displaying an orientation to the particular conduct/action prompting repair, or being marked in some way or other. By looking at the ways the participants treat these interactional moments, an analyst can get at the underlying norms (see Hutchby \& Wooffit, 1998, for discussion of deviant case analysis).

In the current data set, there are a number of these deviant cases, where the stepwise move into this business-at-hand is momentarily suspended along the same lines as discussed in Example 2. Here, we will discuss one of the instances where it is the staff member whose language repertoire becomes a topic requiring attention prior to the service encounter proceeding. In this excerpt, a client approaches the help desk counter and he and the staff member enter into an encounter. However, the meeting hits trouble when the staff member initiates medium repair (Gafaranga 2000) from Danish to English. 

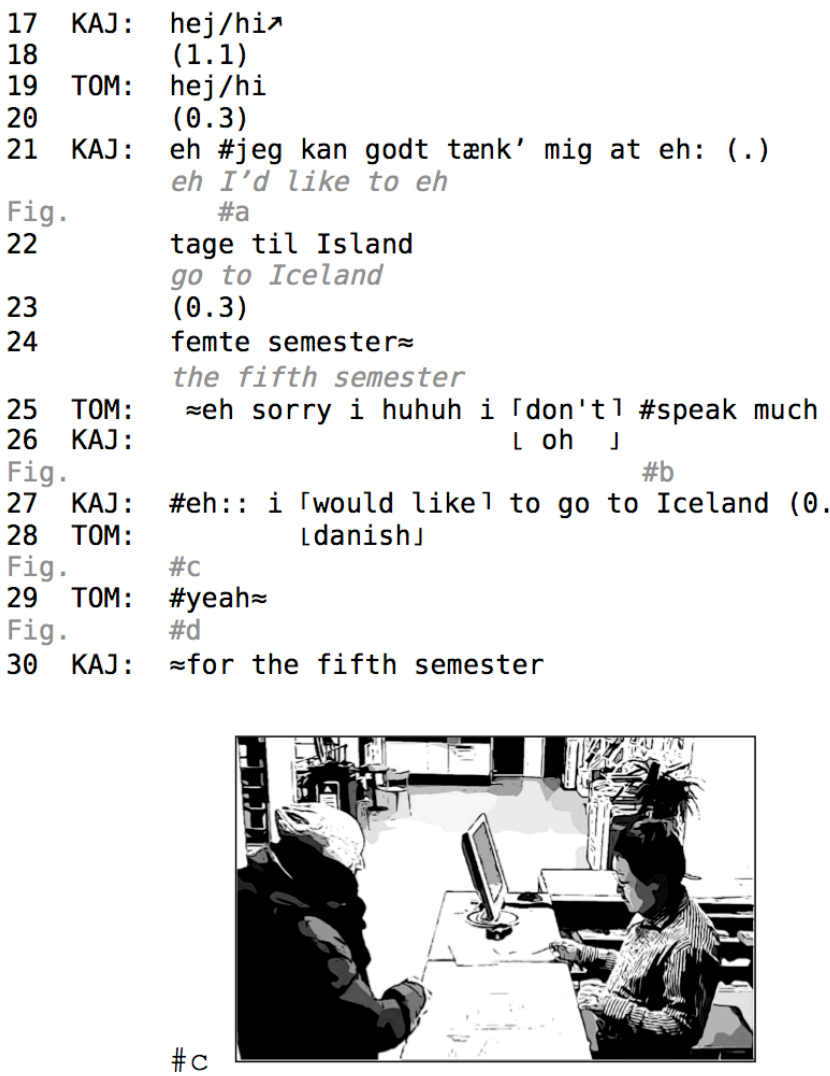
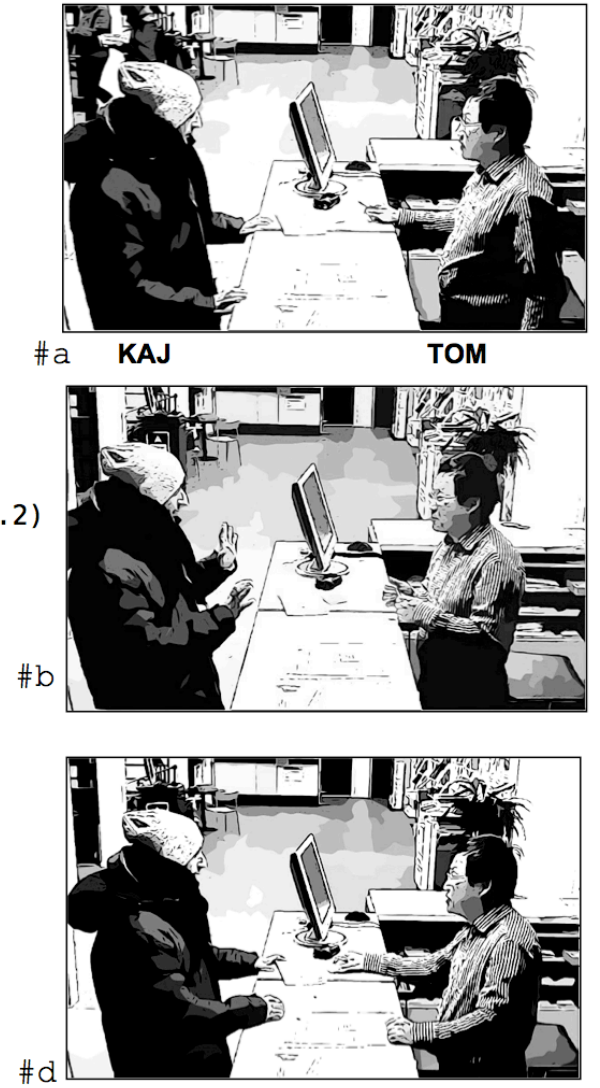

We note the canonical opening sequence described earlier (lines 17-19). Following this pattern the client is again in the position to treat the second greeting, produced by the staff member in response to his own, as being in either English or Danish. He subsequently embarks on formulating the topic of the enquiry, selecting Danish to do so. At the point in which we normally observe a 'continuer' token on the part of the staff member, here the staff member occasions a suspension of the unfolding multiunit turn. He offers an apology for not being able to speak Danish, formatted with laughter tokens (line $25 \& 28$ ). This apology acts as what Schegloff (2005) has described as a retro-acting object, prompting a search for possible 'complainable' conduct located in the prior talk. As soon as the clerk's choice of English is identifiable ('sorry I huhuh', line 25), and the trouble source thus recognizable, the apology is downplayed by the client. This is a preferred next action to an apology (Robinson, 2004). He removes his hands from the counter and brings them up to chest height (Fig. b) in a demonstrative gesture of disputing the relevance of the apologizing - either by a 'warding off' of the apology, or producing this as an apologetic gesture in its own right, acknowledging the mis-categorizing of the staff member as a Danish speaker. Whichever reading one takes, the gesture acts to attenuate the staff member's transgression (Robinson, 2004), although not without locating the 'complainable', which is here the clerk's inability to conduct the encounter in Danish. The client subsequently restarts his turn, this time in English.

The participants here negotiate an explicit repair of the medium-of-interaction (Gafaranga 2000), but what is more, it is produced in a dispreferred format (Schegloff, Jefferson \& Sacks, 1977; Pomerantz 1984): it is delayed, disfluent, includes hesitation markers, with an explicit apology and account for the repair initiation on the part of the staff member. These formatting components appear to 
orient to an understanding of the staff member's Danish language proficiency being a cause of interactional trouble, and hence being a valid expectation on the part of a client.

The lack of Danish is thus arguably treated as a relevant deficiency on the part of his membership in the category relating to his institutional position. The staff member is oriented to by both parties as not type-fitting the membership category relating to his institutional identity, with Danish being accountably absent. This indicates that not being able to speak in the client's preferred language is a sensitive issue which touches on what Garfinkel (1964:225) refers to as the moral order:

A society's members encounter and know the moral order as perceivedly normal courses of action familiar scenes of everyday affairs, the world of daily life known in common with others and with others taken for granted.

Breaches in the everyday normality or affairs attract attention, result in anxiety, moral and psychological evaluations even, and can threaten the status of the breacher, in this case the member of staff.

Schegloff $(2005, \mathrm{p} 452)$ has argued that the "complainability of some form of conduct can be contingent on the identity of the agents and the recipients of the conduct-identities often grounded in category memberships", and that this can be seen to be oriented to, even in the absence of an explicit complaint. The upshot of perturbations such as that featured in the above example is that the member of staff is oriented to by both the client and the staff member himself as deviating from the normative expectations pertaining to the membership category 'International Office staff member', at least with regard his linguistic identity. Of course, this is not treated explicitly as problematic on the part of those who come into contact with him: it is implicit in the way expectations are displayed as requiring recalibration. With each occasion potentially flagging up the misalignment between the institutional position that he holds and his linguistic repertoire, these repair sequences may then act to undermine his institutional identity and confidence as a fully competent member of staff, indeed potentially bringing about a marginalization of particular members of the workplace community. This supports findings documented elsewhere by survey based studies such as Ehrenreich (2010) and Neeley (2013).

\subsubsection{Coda: Adopting strategies for avoiding explicit medium repair}

Elsewhere (Hazel, to appear), I have described a number of strategies (not always successful) that this particular member of staff has adopted, which serve to circumvent the type of interactional trouble analysed here, and micro-manage the entry into the encounter. First there is the pre-emptive strike, where he avoids the greeting sequence altogether and opens the interaction with a turn that is clearly, unambiguously English. This exploits the preference for same language across turns (Auer, 1984; Gafaranga, 2000; Nevile \& Wagner, 2008), constraining the language choice of his co-participant. Second, he is seen drawing on resources in the environment, his receptive language competence in Danish or a related language, and his understanding of the range of topics common to the service requests in order to respond to clients' opening turns, while in the process performing embedded medium repair (Gafaranga, 2010) from Danish to English. The adoption of such strategies would appear to indicate a disposition to avoid such situations where his linguistic identity is indexed against his institutional membership category, with the potentially negative ramifications for his professional identity. 
We note that in order to avoid a topicalising of the staff member's 'deficient' language repertoire in this way, he or she is able to draw on a range of resources to micro-manage the trajectory into the service encounter. Doing so allows for the staff member to forestall the adoption of a 'problematic' language as medium-ofinteraction, or alternatively to prompt the client to switch to the staff member's preferred medium. Furthermore, this is done without occasioning an explicit language negotiation sequence, where the staff member's language competencies are flagged up as being at odds with normative expectation.

The analyses presented here demonstrate how language repertoires, preferences, and competencies are indexed against members' institutional roles. Where these linguistic identities do not meet with normative expectations regarding a particular institutional position, this may be flagged by the parties as deviant, and business that needs attending to for the interaction to proceed. These sequences display many hallmarks of being dispreferred: they are disfluent, delayed and require of the 'deviant' member to provide an account for the non-compliance with normative expectations. This perceived deviance may in turn act to unintentionally compromise the institutional identities of particular members of the community, leading to potential marginalization.

\section{Discussion \& Conclusion}

We opened with a discussion of how language repertoires and competencies, in sum one's linguistic identity, are indexed against particular membership categories, including those related to professional or institutional identities. The subsequent analyses focused on workplace settings constituted by linguistically diverse populations of staff and clients, where language selection is oriented to as a members' issue. For example, a particular category-bound predicate associated with the institutional status of team members in an international company in Denmark is the unproblematic, confident use of English during workplace meetings, regardless of the personal preferences or competences of the team members to do so. Elsewhere, in a Danish university setting, international students are expected to lack proficiency in the local language, while staff at the International Office help desk are expected to be at least bilingual in Danish and English, regardless of their institutional role within the organisation. Where this is not the case, as in the examples offered here, participants display an orientation to this non-observance (Spolsky \& Shohamy 2000), treating the members as deviating from normative expectations relating to their membership category, and therefore not conforming to their respective institutional identities. As a consequence, workplace members' linguistic identities are indexed as other-than-the norm, suggesting that this otherness in fact works as a process of implicit evaluation within particular communities of practice. In the same way a member of staff can be held accountable for being unable to accommodate the line manager or the client in terms of carrying out their job, or addressing the particular issue that has prompted a service encounter, the staff member can also be held morally accountable for what language repertoire is available for carrying out the tasks.

The overriding theme for the Special Issue is a critical exploration of how working in highly interconnected and multicultural workplace communities shapes language and sociocultural practices, and offers a set of discussions of the methodological challenges and opportunities that these transient settings offer the field of language and intercultural communication. The current paper has sought to demonstrate how 
empirical accounts of situated language practice can enhance our understanding of how language policy, language ideology and language attitudes play out in the field, with consequences for the institutional or professional identities of the members in these communities. The particular emic perspective developed through CA- and MCA-inspired analyses is especially beneficial here, as it allows for researchers to develop empirically grounded accounts of the ways in which members in the workplace communities produce social order in situ, through the micro-managed social practices evidenced in interaction, including sequential organisational practices of turn-taking, repair strategies, accounting practices, and orientations to deviance.

Although discursive approaches to the analysis of institutional and professional identities have gained in momentum of the last number of years, studies of identities as they emerge in the carrying out of everyday work practices, especially those studies using recordings of 'real-life' encounters, are still very much in the minority (Bargiela-Chiappini, 2011). The corrective offered here and similar work elsewhere (e.g., Day, 1994; Markaki et al, 2010), does not seek to underplay the insights generated by the types of study that investigate the interplay of linguistic and professional identities within international workplace settings, which have been conducted using other methodological tools, such as quantitative survey reports (e.g., Harzing \& Pudelko, 2012), qualitative survey tools (e.g., Ehrenreich, 2010; Neeley, 2013; Mahili, 2014), ethnographic observation or mixed-method approaches that combine ethnographic fieldwork with survey tools (e.g., Lauring, 2008; Lønsmann, 2014). Rather, interaction analytic accounts such as the one presented here aim to contribute to this field of scholarship, by offering insight into the moment-by-moment enactment of social order, including at the level of identity negotiation.

I will discuss this with two examples. First, interaction analytic research can offer additional nuance to studies in the field of transnational mobility. For example, where a recent critique by Canagarajah (2013) has sought to offer greater granularity to the sociolinguistics of globalisation as represented by Blommaert and colleagues (e.g. Collins, Baynham, \& Slembrouck, 2009; Blommaert, 2010), which he argues employs too blunt a conceptualisation of scalarity to be able to account for the agency of migrant workers as they re-negotiate their linguistic identities within their new, translocal sociolinguistic environments, his own study draws on interview data with migrants, which is still some distance removed from the settings themselves (a point acknowledged himself). More immediate scrutiny of the interactions in which people are involved, as featured in the current study, affords both of these lines of research a window into how such agency is constituted, contested, negotiated and resolved between the parties to these encounters in situ. Hence, we are able to develop a different level of insight: that of how participants display between one another their respective understanding of what norms, expectations, rights and obligations are deemed relevant for this moment, in this activity, in this setting with respect to language and indexicality. Consequently, we are in the position to build up a fuller, more fine-grained account of the fleeting moments where identity work is being occasioned, where people place one another within a matrix of social order; practices which would be difficult to explicate through even the most detailed accounts elicited through survey tools such as interviews. Where Canagarajah's study, and those aforementioned studies such as Neeley (2013) and Ehrenreich (2010) can report on some outcomes of workplace internationalisation on members' experiences of how this impacts on their position, self-esteem and perceived agency within their workplace communities, interaction analytic investigations can shed light on the very processes from which these accounts result. 
Second, this line of research continues to add to theoretical work on discursive identities, and more broadly on theorising identity. Looking at the internationalised work setting, Lauring (2008), for example, explores how L1 differences may impact on the formation of in-group social identities among workplace members. Here, he critiques Social Identity Theory (e.g., Tajfel, 1982) with what he perceives as its linear link between language and identity, criticising this conceptualisation as too deterministic and static, and arguing for a more dynamic consideration of language use as a means for strategic self-representation in the transnational workplace. In transient multilingual settings and communities such as those featured here, we can explore this further, and show how it is not necessarily the L1 background that becomes the relevant object within institutional activities, but a member's available language arsenal, language preferences, and competences; in sum, their linguistic identity and how this accommodates whichever institutional identity is oriented to as relevant to that encounter. It is the linguistic resources that a member is able to mobilize that is here the relevant object of identification (Lauring, 2008) with relation to one's institutional category, rather than this or that language, or the particular (L1 or L2) status of the language to the user.

With an increasing number of institutional settings becoming internationalised, the findings presented here have important implications for workplaces characterised by transnational mobility. Increasing an awareness of social practices that link professional identities with other social identity constructs such as ethnicity, nationality, or in this case linguistic identity, can 1. prepare the ground for avoiding the potential pitfalls of group fragmentation, anxiety, alienation and isolation experienced by particular members of the workplace community (e.g., Deneire, 2008), 2. promote greater mutual accommodation between divergent normative expectations; and 3. promote further understanding of the longer term impact that such deviance-marking may have on a member's upward social mobility within the workplace. The shifting sands of the increasingly transnational workplace settings that have recently become so commonplace across the globe, offer both practitioner and researcher an opportunity to reconsider sedimented understandings of community membership and belonging, social identity formation and workplace practices, and explore afresh the dynamic processes involved in the constitution of workplace - and other types of - communities.

\section{APPENDIX Transcription conventions}

The transcription conventions are based on those developed by Gail Jefferson (e.g. 2004). Some are used in modified form for use in the CLAN software tool (MacWhinney \& Wagner 2011). 
Identifier

Pause

Overlap markers top

Overlap markers bottom

Intonation: rising

continuing

falling

Pitch shift

Latched turns

Smiley voice

Inbreath

Stress

Accelerated speech

Translation
TEA :

(0.2)

「 1

L」

$\pi$

$\rightarrow$

$y$

$\uparrow$

$\approx$

(:)

. hhhh

now

$\Delta$ and you $\Delta$

In italics 


\section{REFERENCES}

Angouri, J. \& Miglbauer, M. (2014). 'And then we summarise in English for the others': The lived experience of the multilingual workplace. Multilingua 33(1-2), 147-172

Antaki, C., \& Widdicombe, S. (1998). Identities in Talk. London: Sage.

Auer, P. (1984). Bilingual conversation. Amsterdam: Benjamins.

Bargiela-Chiappini, F. (2011). Foreword. In J. Angouri \& M. Marra (Eds.) Constructing Identities at Work, Basingstoke: Palgrave Macmillan

Blommaert, J. (2010). The sociolinguistics of globalization. Cambridge: Cambridge University press.

Bonacina-Pugh, F. (2012). Researching 'practiced language policies': insights from conversation analysis. Language Policy 11:213-234

Brassac, C., Fixmer, P., Mondada, L., \& Vinck, D. (2008). Interweaving Objects, Gestures, and Talk in Context. Mind, Culture, and Activity, 15(3), 208 - 233.

Canagarajah, S. (2013). Agency and power in intercultural communication: negotiating English in translocal spaces. Language and Intercultural Communication 13(2), 202-224

Collins, J., Baynham, M., \& Slembrouck, S. (Eds.). (2009). Globalization and language in contact: Scale, migration, and communicative practices. London: Continuum.

Day, D. (1994). Tang's dilemma and other problems: ethnification processes at some multicultural workplaces. Pragmatics 4(3), 315-336

Deneire, M. (2008). English in the French workplace: realism and anxieties. World Englishes, 27(2), 181-195

Ehrenreich, S. (2010). English as a Business Lingua Franca in a German Multinational Corporation: Meeting the Challenge. Journal of Business Communication 47, 408-431

Gafaranga, J. (2000). Medium repair vs. other-language repair: Telling the medium of a bilingual conversation. International Journal of Bilingualism, 4:327-350.

Gafaranga J. (2001). Linguistic identities in talk-in-interaction: Order in bilingual conversation. Journal of Pragmatics, 33, $1901-1925$.

Gafaranga J. (2010). Medium request: Talking language shift into being. Language in Society, $39(02), 241-270$.

Gafaranga, J., \& Torras, M.-C. (2001). Language versus Medium in the study of bilingual conversation. International Journal of Bilingualism, 5: 195-219

Garfinkel, H. (1964). Studies of the routine grounds of everyday activities. Social Problems, 11(3), pp. 225-250

Garfinkel, H. (1967). Studies in Ethnomethodology, Englewood Cliffs, NJ: Prentice-Hall.

Goebel,Z. (2010). Identity and social conduct in a transient multilingual setting. Language in Society, 39, 203-240

Goffman, E. (1981). Forms of talk. Oxford: Blackwell.

Goodwin, C. (1981). Conversational Organization: Interaction Between Speakers and Hearers. New York: Academic Press.

Goodwin, C. (1994). Professional Vision. American Anthropologist, 96(3), 606-633.

Goodwin, C. (2007). Participation, stance and affect in the organization of activities. Discourse \& Society, 18(1), 53-73.

Goodwin, C., \& Heritage, J. (1990). Conversation analysis. Annual Review of Anthropology, 19, 283-307.

Greiffenhagen, C., \& Watson, R. (2009). Visual repairables: analysing the work of repair in human-computer interaction. Visual Communication, 8(1), 65-90.

Gunnarsson, B-L. (2014) Multilingualism in European workplaces. Multilingua 33(1-2): 1133

Harzing, A-W. \& Pudelko, M. (2012). Language competencies, policies and practices in multinational corporations: a comprehensive review and comparison of Anglophone, Asian, Continental European and Nordic MNCs. Journal of World Business 48 (1), 87-97

Hazel, S. (2012). Interactional competence in the institutional setting of the international university. Ph.d. thesis. Roskilde: Roskilde University 
Hazel, S. (to appear). Conflicting identities - an interaction analytic account of institutional identity negotiation in multilingual workplace settings. In Lubie Alatriste (ed.) Discourse Studies in Diverse Settings: Dissemination and Application. Clevedon, England: Multilingual Matters

Hazel, S. \& Mortensen, J. (2013). Kitchen talk - Exploring linguistic practices in liminal institutional interactions in a multilingual university setting. In H. Haberland, D. Lønsmann and B. Preisler, (Eds.) Language Alternation, Language Choice and Language Encounter in International Tertiary Education. Dordrecht: Springer

Hazel, S. \& Mortensen, K. (2014). Embodying the institution - multimodal practices in developing interaction in study counselling meetings. In G. Rasmussen, K. Mortensen and S. Hazel (eds.) Special Issue: 'A body of resources - CA studies of social conduct', Journal of Pragmatics 65, 10-29

Heath, C. (2002). Demonstrative Suffering: The Gestural (Re)embodiment of Symptoms. Journal of Communication, 52(3), 597-616.

Heller, M. (1982). Negotiation of language choice in Montreal. In J. Gumperz (Ed.), Language and social identity (pp.108-118). Cambridge, U.K.: Cambridge University Press.

Heritage, J. (1984). A change-of-state token and aspects of its sequential placement. In J. M. Atkinson \& J. Heritage (Eds.), Structures of social action: studies in conversation analysis: Cambridge University Press.

Heritage, J. (1997). Conversation analysis and institutional talk. In David Silverman (Ed.), Qualitative research: Theory, method and practice (pp. 161-182). Thousand Oaks, CA: Sage.

Hester, S., \& Eglin, P. (1997). Membership categorization anlaysis: an introduction. In S. Hester \& P. Eglin (Eds.), Culture in action: Studies in membership categorization analysis (pp. 1-23). Washington D.C.: International Institute for Ethnomethodology and Conversation Analysis \& University Press of America.

Hindmarsh, J., Heath, C., Vom Lehn, D., \& Cleverly, J. (2005). Creating Assemblies in Public Environments: Social Interaction, Interactive Exhibits and CSCW. Computer Supported Cooperative Work (CSCW), 14(1), 1-41-41.

Hultgren, A.K. (2014). Whose parallellingualism? Overt and covert ideologies in Danish university language policies. Multilingua 33(1-2), 61-87

Hutchby, I. \& Wooffit, R. (1998). Conversation analysis. Cambridge: Polity Press

Jefferson, G. (2004). Glossary of transcript symbols with an introduction. In G. Lerner (Ed.) Conversation Analysis. Studies from the First Generation. (pp. 13-32). Amsterdam: John Benjamins.

Koschmann, T., LeBaron, C., Goodwin, C., \& Feltovich, P. (2011). "Can you see the cystic artery yet?" A simple matter of trust. Journal of Pragmatics, 43(2), 521-541.

Kurhila, S. (2006). Second Language Interaction. Amsterdam: Benjamins.

Lauring, J. (2008). Rethinking Social Identity Theory in International Encounters: Language Use as a Negotiated Object for Identity Making. International Journal of Cross Cultural Management 8, 343-361

Lønsmann, D. (2011). English as a corporate language. Language choice and language ideologies in an international company in Denmark. PhD Thesis, Roskilde: Roskilde University

Lønsmann, D. (2014). Linguistic diversity in the international workplace: Language ideologies and processes of exclusion. Multilingua 33(1-2), 89-116

Mahili, I. (2014). 'It's pretty simple and in Greek...': Global and local languages in the Greek corporate setting. Multilingua 33(1-2), 117-146

Markaki, V., Merlino, S., Mondada, L., \& Oloff, F. (2010). Laughter in professional meetings: The organization of an emergent ethnic joke. Journal of Pragmatics, 42(6), 1526-1542.

MacWhinney, B., \& Wagner, J. (2010). Transcribing, searching and data sharing: The CLAN software and the TalkBank data repository. Gespraechsforschung, 11, 154-173.

Mondada, L. (2004). Ways of "Doing Being Plurilingual" in International Work Meetings. In: Gardner, R., Wagner, J. (Eds.), Second Language Conversations. Continuum, London, $27-$ 60. 
Mondada, L. (2009). Emergent focused interactions in public places: A systematic analysis of the multimodal achievement of a common interactional space. Journal of Pragmatics, 41(10), 1977-1997.

Mori, J., \& Hasegawa, A. (2009). Doing being a foreign language learner in a classroom: Embodiment of cognitive states as social events. IRAL - International Review of Applied Linguistics in Language Teaching, 47(1), 65-94.

Mortensen, J. (2010). Epistemic stance marking in the use of English as a lingua franca., Roskilde University, Roskilde.

Mortensen, J. (2013). Notes on the use of English as a lingua franca as an object of study. Journal of English as a Lingua Franca 2(1). 25-46.

Mortensen, J. (2014). Language policy from below:: Language choice in student project groups in a multilingual university setting. Journal of Multilingual \& Multicultural Development. 35 (4), 425-442

Mortensen, K., \& Hazel, S. (2011). Initiating round robins in the L2 classroom-preliminary observations. Novitas-ROYAL (Research on Youth and Language), 5(1), 55-70.

Mortensen, K. \& Hazel, S. (2014). Moving into an interaction - embodied practices for initiating interactions at a help desk counter. Journal of Pragmatics 62, 46-67

Murphy, K. M. (2005). Collaborative imagining: The interactive use of gestures, talk, and graphic representation in architectural practice. Semiotica, 156, 113-145.

Neeley, T.B. (2013). Language Matters: Status Loss and Achieved Status Distinctions in Global Organizations. Organization Science 24(2), 476-497

Nekvapil, J., \& Nekula, M. (2006). On language management in multinational companies in the Czech Republic. Current Issues in Language Planning, 7, 307-27.

Nevile, M., \& Wagner, J. (2008). Managing Languages and Participation in a Multilingual Group Examination. In H. Haberland, J. Mortensen, A. Fabricius, B. Preisler, K. Risager \& S. Kjærbeck (Eds.), Higher Education in the Global Village (pp. 149-175). Roskilde: Roskilde Universitetscenter.

Nishizaka, A. (2006). What to Learn: The Embodied Structure of the Environment. Research on Language \& Social Interaction, 39(2), 119 - 154.

Pomerantz, A. (1984). Agreeing and disagreeing with assessments: Some features of preferred/ dispreferred turn shapes. In J. M. Atkinson \& J. Heritage (Eds.), Structures of social action: Studies in conversation analysis (pp. 57-101). Cambridge: Cambridge University Press.

Raudaskoski, P. (2010). "Hi Father", "Hi Mother": A multimodal analysis of a significant, identity changing phone call mediated on TV. Journal of Pragmatics, 42(2), 426-442.

Robinson, J.D. (2004). The sequential organization of "explicit" apologies in naturally occurring English. Research on Language \& Social Interaction 37: 291-330.

Sacks, H, (1972). An initial investigation of the usability of conversational data for doing sociology. In: Sudnow, D. (Ed.), Studies in Social Interaction. New York: Free Press, pp. 31-74.

Sacks, H. (1979). Hotrodder: A revolutionary category. In G. Psathas (Ed.), Sociocultural dimensions of language use (pp. 7-14). New York: Irvington.

Sacks, H. (1992). Lectures on conversation. Gail Jefferson (Ed.). Oxford: Blackwell.

Sacks, H., Schegloff, E.A. \& Jefferson, G. (1974). A simplest systematics for the organization of turn-taking for conversation. Language 50:696-735.

Schegloff, E. A. (1972). Sequencing in conversational openings. In: J. J. Gumperz and D. Hymes, (Eds)., Directions in sociolinguistics, 346-380. New York: Holt, Rinehart and Winston.

Schegloff, E.A., Jefferson, G., \& Sacks, H. (1977). The preference for self-correction in the organisation of repair in conversation. Repr. in G. Psathas (ed.), Interactional competence, 31-62. Washington, DC.: International Institute for Ethnomethodology and Conversation Analysis 1990.

Schegloff, E.A. (2005). On Complainability. Social Problems 52: 449-476.

Spolsky, B. (2004). Language policy. Cambridge, England: Cambridge University Press.

Spolsky, B. (2007). Towards a theory of language policy. Working Papers in Educational 
Linguistics 22(1):1-14.

Spolsky, B. \& Shohamy, E. (2000). Language practice, language ideology, and language policy. In R.D. Lambert and E. Shohamy eds. Language policy and pedagogy: Essays in honour of A. Ronald Walton. 1-41. Amsterdam: Benjamins

Tajfel, H. (1982). Social Psychology of Intergroup Relations. Annual Review of Psychology 33: $1-39$.

Torras, M.-C. (1998). Catalan, Castilian or both? Code negotiation in bilingual service encounters. Working Paper, 96. Center for Language in Social Life. University of Lancaster.

Torras, M.-C. (2005). Social identity and language choice in bilingual service talk. In K. Richards \& P. Seedhouse (eds.), Applying Conversation Analysis, 107-123. Basingstoke: Palgrave Macmillan.

Woolard, K. A. (1999). Strategies of simultaneity and bivalency in bilingual communication. Journal of Linguistic Anthropology 8:3-29.

Zimmerman, D. H. (1998). Identity, context and interaction. In C. Antaki \& S. Widdicombe (Eds.), Identities in talk (pp. 87-106). London: Sage. 